\title{
Plant Identification Using Artificial Intelligence: Innovative Strategies for Teaching Food Biodiversity
}

\author{
Elias Jacob de Menezes Neto, Djackson Garcia de Lima, \\ Ivanilda Soares Feitosa, Sávio Marcelino Gomes, \\ and Michelle Cristine Medeiros Jacob
}

\section{Contents}

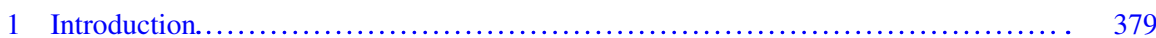

2 Why Did We Create NEIDE? ............................................. 381

2.1 Biodiversity Decline and Lack of Species Literacy.......................... 381

2.2 The Need for a Better Approach in Biodiversity Education.................... 382

2.3 Use of Technology and Innovative Methods............................. 383

2.4 The Idea to Create NEIDE............................................... 384

3 How Did We Elaborate a Web-Based App to Identify Unconventional Food Plants?.... $\quad 385$

3.1 The Dataset................................................... 385

3.2 Architectures Used and Results................................... 386

3.3 Safety Considerations for Model Deployment.......................... 387

4 Educational Implications of NEIDE and Other Innovative Methods................. 389

5 Final Considerations......................................................... 390

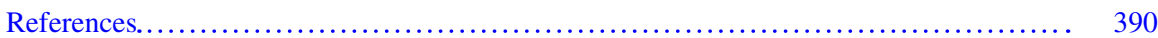

\section{Introduction}

"People care about what they know" (Balmford 2002). For this reason, species literacy, which involves species identification skills, is a pillar of projects engaged in biodiversity conservation (Aldhebiani 2018). There is evidence that species knowledge is associated with positive attitudes toward both fauna and flora conservation (Hooykaas et al. 2019). Within the biophilia hypothesis of Edward Osborne Wilson,

E. J. de Menezes Neto $(\varangle) \cdot$ D. G. de Lima · S. M. Gomes · M. C. M. Jacob

Universidade Federal do Rio Grande do Norte, Natal, Brazil

e-mail: eliasjacob@ufrn.edu.br; djackson7@ufrn.edu.br; saviogomes@ufrn.edu.br; michellejacob@ufrn.edu.br

I. S. Feitosa (Deceased)

Universidade Federal de Pernambuco, Laboratório de Ecologia e Evolução de Sistemas

Socioecológicos, Recife, Brazil 
biodiversity teaching projects find a good argument: human beings have an innate desire to catalog, understand, and spend time with other forms of life (Wilson 1984). However, studies in many countries where biodiversity education has been in place for decades (e.g., Finland, Sweden) reveal that people, even when involved in such projects, do not always perceive plants well or identify species (Randler 2008; Salatino and Buckeridge 2016; Yli-Panula et al. 2018). A probable explanation is that as industrialization and urbanization reduce our direct interactions with nature, our species' biophilic potential is redirected toward human artifacts (Balmford 2002). Technological devices, for example, are seen as reducing interactions between humanity and the environment, with the resulting consequence of little or no species literacy (Neves et al. 2019).

Some authors argue that technology can be a solution (instead of a problem) in biodiversity education projects (Rogers et al. 2004; Pfeiffer et al. 2009; March 2012; Sung et al. 2016). They understand technology as a means of teaching biodiversity-related topics and arousing the interest of generations more engaged with technology. One application in education technology is "mobile learning" or "M-learning," a modality of e-learning in which learning occurs through mobile devices, such as cell phones or tablets (Pfeiffer et al. 2009). In these cases, mobile devices are seen as tools which support the learning process, reducing the gap between the real world and classroom experiences, by transporting the information used in the room to the outside world and vice versa. M-learning initiatives, such as the "Encyclopedia of Life," can involve new audiences outside the scientific community and allow them to contemplate the richness, beauty, and relevance of biodiversity in our lives (Wilson 2003).

M-learning has proven to be more successful than traditional learning methods in producing educational outcomes (Sung et al. 2016). Some researchers have already tested M-learning in the field of biodiversity education. As an example, Yvonne Rogers et al. (2004) designed an outdoor learning experience, in the forest with teenagers, to encourage contextualized scientific biodiversity research. The study confirmed that this type of exploration promotes interpretation and reflection and has better results than traditional methods. Technologies involving direct interaction between subjects (e.g., Crowdmap, using volunteered geographic information) enable construction of complex collaboration networks between individuals while simultaneously stimulating connectivity and cooperation (Hemingway et al. 2015).

Tools that combine the use of mobile devices with artificial intelligence (AI) can also be powerful instruments in biodiversity education. "AI is a branch of computer science, and is concerned with construction and deployment of intelligent agents as computer programs and with understanding the behavior of these artifacts" (Feldman 2001, p. 792). AI already has several applications in education, such as adaptive platforms (e.g., Khan Academy, Geek, among others), that recognize student learning patterns and use them to improve strategies that increase student motivation

\footnotetext{
${ }^{1}$ See at: https://eol.org/
} 
and engagement (Gatti 2019). For biodiversity, in addition to engaging young audiences with nature, AI apps address practical problems related to biodiversity conservation, such as rapidly identifying species menaced by extinction (Kwok 2019). The data processing potential of AI is crucial in responding to the current biodiversity loss crisis, guiding on-time decision-making.

This chapter discusses our development of a web-based app, trained with artificial intelligence to identify nine unconventional food plants (UFP) in a community garden in Northeastern Brazil. During their activities in the garden, participants were encouraged to visit a website, choose a plant, take a picture with their mobile devices, and submit them for identification to learn more about the species; and then to evaluate the classification provided by our model. We named this app NEIDE (NEural IDEntifier) in honor of Neide Rigo (also an author in this book), one of the Brazilian women who inspired us with her vast knowledge of UFP. ${ }^{2}$ To build NEIDE, we used a convolutional neural network (CNN), an architecture that has successfully applied AI in a wide range of image classification tasks (including plant image identification), performing in state-of-the-art models, as well as human experts. Before presenting the elaboration of NEIDE, we will provide a narrative summary of the main ideas that supported our product's idea. Finally, we will finish our chapter by discussing the implications of using innovative products in education projects - in both formal and informal learning spaces (e.g., schools, school gardens, and community gardens).

\section{Why Did We Create NEIDE?}

\subsection{Biodiversity Decline and Lack of Species Literacy}

The current data concerning biodiversity losses are alarming. A recent report by the "Intergovernmental Science-Policy Platform on Biodiversity and Ecosystem Services" (2019) has revealed that biodiversity is declining more rapidly than at any other time in history, with the average abundance of native species in most major terrestrial habitats dropping by at least $20 \%$ since 1900 . The report also shows that more than 1,000,000 species are currently under threat of extinction. It is unlikely that scholars will be able to describe even a small part of our biodiversity before it is extinguished. In Brazil, the leading causes of this loss are intensive agricultural activity (da Silva 2018) and unsustainable extraction of forest products (Lima et al. 2012; Nunes et al. 2012; Feitosa et al. 2017). In the Cerrado biome, agricultural degradation increases biodiversity loss and food insecurity (Cunha et al. 2008; Lima et al. 2012). The Caatinga (after the Atlantic Forest and the Cerrado) is considered the third most degraded biome in Brazil, with $80 \%$ of its vegetation modified by deforestation (Souza et al. 2015).

\footnotetext{
${ }^{2}$ Code and data available at https://github.com/eliasjacob/neide
} 
The lack of interactions between people and nature is both cause and consequence of this rapid decline in biodiversity (Soga and Gaston 2016): cause, because when we interact little with biodiversity, we learn little about it (Hooykaas et al. 2019), and thus, the greater tendency toward alienation concerning the problem of environmental degradation and its consequences (Rozzi 2013), and consequence because the reduction of green spaces caused by deforestation reduces people's opportunities to interact with plant, animal, and fungi species and even with other human beings (in parks, for instance) (Celis-Diez et al. 2017).

Biodiversity education projects aim to break this harmful cycle. A primary objective of many initiatives of this nature is to increase species literacy. Species literacy involves a broad and deep knowledge about species, starting with identification skills (Aldhebiani 2018). Yet, species literacy also involves awareness of species diversity (species richness), positioning in the ecological food chain (trophic level), natural life environment (habitat), lifecycle knowledge (e.g., insect egg-larva-adult metamorphosis), knowledge of origins (whether native, exotic, or cultivated), and conservation status (abundant, threatened, or extinct) (Hooykaas et al. 2019).

\subsection{The Need for a Better Approach in Biodiversity Education}

As already mentioned, even in countries where biodiversity education has been a topic for decades, species literacy lacks much. The EU has had legislation on biodiversity conservation and education since the 1970s. Yet in the "Attitudes Towards Biodiversity" (2013) survey, assessing the population's knowledge of biodiversity, the European Commission interviewed roughly 25,000 citizens over the age of 15 across the European Union (EU), and the results revealed that after more than 40 years of effort, $44 \%$ of Europeans did not even know what the term "biodiversity" meant. Three out of ten knew the term, but did not know what it meant, and a quarter of the interviewees had never even heard of biodiversity. Other research (Bebbington 2005) has demonstrated that even among A-level students in biology, the ability to recognize and name common wildflowers, for example, tends to be low; the students thought that naming organisms was not an important ability and showed little interest in learning identification skills.

Teaching methods are a contributing factor for low engagement in developing biodiversity skills. Teachers who coordinate biodiversity projects frequently simply reproduce the model they know from their own training yet without contextualizing the topic to the student's reality (Silva 2013). Subjects involving botany, for example, are often taught in a mnemonic and annoying way, where the students do not recognize applications in their daily lives (da Fonseca and Ramos 2019). Consequences for a society that does not recognize its plants are drastic, and thus there is an urgent need to break this vicious cycle in science education. Ignorance of the importance of trees in rural and urban environments leads a society to stop caring about its environment and thus toward destruction of its own ecosystem (Salatino and Buckeridge 2016). 
In a literature review, Navarro-Perez and Tidball (2011) identified inadequate communication as a principal obstacle toward achieving biodiversity educational outcomes. Textbooks, still considered the primary tool in the teaching and learning process, reveals this low capacity to communicate and attract the public. The content presented in such materials does little to contribute to a comprehensive understanding of biodiversity at either global or local levels, as well as not stimulating a critical understanding of nature conservation (de Fonseca 2007). As a result, student engagement is low, and despite growing public concern, environmental issues still rank below many other problems, such as terrorism, health, economics, and family values (Novacek 2008).

\subsection{Use of Technology and Innovative Methods}

The United Nations recommends development of platforms that allow young people to positively connect with biodiversity conservation (United Nations Environment Programme 2019). They argue that in biodiversity projects, the use of technology may expand young people's interaction with nature and, consequently, their engagement and learning outcomes.

Costa Rica, for example, internationally recognized for its biological diversity, is a reference country in promoting educational strategies for biodiversity conservation. Jiménez et al. (2017) report that significant progress toward biodiversity conservation has been achieved through programs that implement innovative teaching methodologies, where technology plays an important role. Virtual learning communities, such as the project "Cibercolmenas" (CyberHive, in English), promote innovative use of science and technology in the classroom, the field, and cyberspace, aiming to generate practical experiences and projects that stimulate student learning of biodiversity in both primary and secondary schools (Zamora and Calvo 2012). Another innovative way to teach biodiversity is through the use of robotics. Ruiz Vicente et al. (2020) developed an application using robotics as a teaching tool in a project involving "sustainability," which presented promising educational outcomes and demonstrated how technology is a potentially active learning tool. In the context of undergraduate education, the tool "CROPVIEW" (Comprehensive Resources for Observing Plants in a Visual Interactive Enhancement Window) through interaction and simulation on a website has the potential to increase students' understanding of global foods, production systems, agricultural practices, plant biology, geography, and climatology. Evaluating the tool, Lori Snyder et al. (2012) argued that "CROPVIEW" used to complement the teaching of environmental sciences appears promising.

The use of innovative methodologies in education is not a new topic. In the 1970s, the behaviorist B. F. Skinner defended what he called "progress in teaching" based on the complementary use of mechanical and electrical artifacts. These artifacts - called "teaching machines" - contained carefully planned material with adaptive characteristics in which the next learning problem would depend on the previous answer (Skinner 1972). The constructivist Seymour Papert also defended 
the computer as a teaching and learning resource. However, differently from Skinner, he argued that in place of a computer-aided instruction methodology, the learner should be the one to program the computer (Papert 1985). He presented a futuristic view of education, believing in the 1980s that we should be taught to communicate with computers (via programming language) to transform the way we learn. Papert was a pioneer in the field of artificial intelligence in education (AIEd).

In the past 30 years, researchers in this field of knowledge have investigated teaching and learning environments along three principal lines of research: (a) intelligent tutoring systems, which provide adaptive and individualized instruction to the learner (e.g., Duolingo); (b) intelligent support for collaborative learning, which supports and enhances group learning processes (e.g., eBird, see below); and (c) intelligent virtual reality, which generates 3D environments to make education more efficient (e.g., Blippar) (Luckin et al. 2016).

AIEd knowledge has also been explored in biodiversity projects that use human and computer learning networks (HCLNs). Such projects leverage networks of volunteers who act as intelligent sensors to collect immediate observations. These are filtered and improved by AI processes to compose aggregated databases capable of providing immediate feedback on the accuracy of the information collected. This in turn contributes to the advancement of the observer's experience, and simultaneously, as the quality of the observer data improves, the training data in which the AI processes make their decisions also improves. The idea is to have robots (by receiving help from a human collaboration network) to perform their tasks, to learn, and to become more autonomous. The eBird initiative, for instance, is a citizen science project that takes advantage of human observational capacity and machine learning methods in a biodiversity conservation and research HCLN (Kelling et al. 2013). eBird engages a global network of bird watchers to identify birds and report their observations to a centralized database. The eBird database content, together with that of other AI-based biodiversity conservation projects, provides scientists, students, and amateur naturalists with data concerning species distribution and abundance across varying spatial-temporal extensions, raising both awareness concerning biodiversity and the potential to increase species literacy.

\subsection{The Idea to Create NEIDE}

Some of us are part of an open-air laboratory, LabNutrir, ${ }^{3}$ which provides a community garden project based at a Brazilian public university. In this space, we develop biodiversity education activities focused on unconventional food plants (UFP) through guided visits, joint projects, and culinary workshops. Each semester we receive up to 500 visitors (primary schools and higher-education students, teachers, and nutritionists among others) interested in learning more about our more than 50 UFP in the LabNutrir.

\footnotetext{
${ }^{3}$ See further information at http://www.nutrir.com.vc/
} 
Our primary purpose is for the laboratory to serve as an education space. The great majority of the signalization (sign posts) within it identifies plant species, which is significant. At the first moment, we fabricated signposts from wood to identify the UFP but, due to the exposure to weather (rain and sun), they did not lasted. So, wanting to boost our teaching practices with "tech," we engaged our students and visitors using active methods such as M-learning. And thus, inspired by the ideas presented in this section and by our practical need, NEIDE was born.

\section{How Did We Elaborate a Web-Based App to Identify Unconventional Food Plants?}

\subsection{The Dataset}

Our entire dataset consists of 2561 photos of 9 species (Bidens pilosa L., Bixa orellana L., Clitoria ternatea L., Commelina erecta L., Costus spiralis (Jacq.) Roscoe, Oxalis regnelli var. triangularis Miq., Peperomia pellucida (L.) Kunth, Plectranthus ornatus Codd., and Portulaca oleracea L.), which were split into 2040 (training) and 521 (validation) labeled photos.

Initially, we took 997 photos for our training dataset. To avoid overfitting (i.e., when a model memorizes a dataset, instead of learning its general characteristics), we designed our training dataset to capture as many plant features as possible. We took photos on 28 different days to capture the plants' attributes during their lifecycles (i.e., with and without flowers) and under several lighting conditions (i.e., cloudy and sunny days, at noon, and sunset) and with different angles and zoom. When collecting our data, we tried to simulate (as much as possible) the final users' behavior, making the model results more robust for small differences in pictures taken by different people, with varied equipment.

Even though we collected photos with differing characteristics, they were naturally similar to one another. To mitigate this problem and to add more diversity to our training dataset, we manually collected and labeled additional 1043 photos from various sources on the Internet. We decided not to use the traditional training/validation random data splits, since this might result in a validation dataset that was artificially similar to our training dataset and undermine our ability to assess our model generalization capabilities accurately. To tackle this issue, we waited 6 months from the first collection to create our validation dataset (composed of 521 labeled images). We hoped that by waiting (due to seasonality), the general landscape and plants would change enough to make our validation dataset substantially different from our training dataset.

We conducted all experiments using the fast.ai library (Howard and Gugger 2020), which provided us with many data augmentation techniques, a critical step toward regularizing computer vision models, since simple changes in the images can result in poor deep neural network performance (Engstrom et al. 2019). With these image transformations, we managed to artificially increase our model's 
exposure to differing target representations by applying several affine transformations and light changes. The following image transformations were randomly applied to our training dataset:

- Horizontal and vertical flipping

- Rotation changes, up to 45 degrees (both to right and left)

- Zoom level changes, up to $1.3 \mathrm{x}$

- Symmetric warping; i.e., tilting the image on all four directions (left, right, top and bottom)

- Contrast and brightness changes

- Resizing and cropping only parts of the full image

All image transformations were applied in tandem, with a probability of $80 \%$. Afterward, we resized them for each training to fit a square, which was then gradually upsampled, allowing our model to capture more information about the target.

\subsection{Architectures Used and Results}

We tested the ResNet (He et al. 2016) and VGG (Simonyan and Zisserman 2015) architectures at varying depths. ResNet is arguably the most used architecture, and newer models generally present the same basic ideas (residual connections between convolutional layers). We decided to use CNNs because they are broadly used for flower (Thanh et al. 2016) and plant identification in the natural environment (Sun et al. 2017). Bodhwani et al. (2019) have successfully used ResNet to identify plants from the LeafSnap dataset, providing a reasonable feasibility baseline.

The models were pre-trained on the ImageNet dataset (Deng et al. 2009), starting with a model already trained for another image classification task and then fine-tuning its weights to our desired goal. This approach is called transfer learning, and it results in better models with far less data than would be required if we had started with randomly initialized weights (Shaha and Pawar 2018). Although Mehdipour Ghazi et al. (2017) have used transfer learning between similar datasets (from one plant identification task to another), we show that one can apply this technique even when the target classification task is intrinsically different from the pre-trained model.

Based on previous tests on other datasets, we added an extra batch normalization to all models, just before the output layer; this slightly improved their accuracy. We also set the learning rate of each parameter group in accordance with the one-cycle learning rate policy described by Smith and Topin (2017). This policy leads to what they describe as super-convergence, which allows neural networks to train much faster than with standard learning rate schedules, boosting the performance in cases like ours, where labeled data is limited.

Our best model achieved an accuracy of $96.35 \%$, with an apparent correlation $\left(R^{2}=0.56\right)$ between the model's capacity (expressed as its number of trainable 
Table 1 Final error rate for each model architecture, considering the number of trainable parameters (better model in bold)

\begin{tabular}{l|l|l}
\hline Model architecture/depth & Error rate $(\%)$ & \# of trainable parameters \\
\hline ResNet 18 & 10.75 & $11,709,019$ \\
\hline ResNet 34 & 4.60 & $21,817,179$ \\
\hline ResNet 50 & 8.83 & $25,619,547$ \\
\hline ResNet 152 & $\mathbf{3 . 6 5}$ & $\mathbf{6 0 , 2 5 5 , 3 2 3}$ \\
\hline VGG 11 & 8.06 & $9,758,473$ \\
\hline VGG 13 & 9.79 & $9,943,369$ \\
\hline VGG 16 & 7.49 & $15,255,643$ \\
\hline VGG 19 & 7.87 & $20,567,881$ \\
\hline
\end{tabular}

parameters) and performance, where larger models (in general) achieved better results. This is evident when we compare the error rate of the smallest ResNet $(10.75 \%)$ with the largest (3.65\%). In Table 1, we present the final error rate for each architecture/size.

Despite our good results, we were dissatisfied working with a black-box model alone, especially considering our educational goals. This led us to look deeper into the model and understand its decisions better. From the work of Selvaraju et al. (2020), which uses gradient-weighted class activation mapping (Grad-CAM) to create visual explanations for a model's output, i.e., the gradient of a label to map important regions of an image, or what is influencing its final decision. We randomly sampled examples from our validation dataset, which enabled us to verify that our model (to classify plant images) was correctly targeting flower and leaf structures. We present two examples below, where relevant areas are seen as brighter spots (Fig. 1).

\subsection{Safety Considerations for Model Deployment}

Our model is readily available for anyone who visits our website, where anyone can submit a sample image for analysis. ${ }^{4}$ Currently, no machine learning model can provide results for a category it is not trained to predict: it will always transform any input into one previously known label. In simpler terms, the model cannot say by itself "I do not know." Any implementation must take this into account.

The model's final layer output (logit scores) consists of an array with one raw score for each class. A softmax function converts these scores into numbers between zero and one (and which sum to one). This can conveniently be interpreted as the probability distribution of potential outcomes for a given input. For the predicted result, the model will choose the label with the highest probability. The limitations

${ }^{4}$ See at http://nutrir.com.vc/neide 

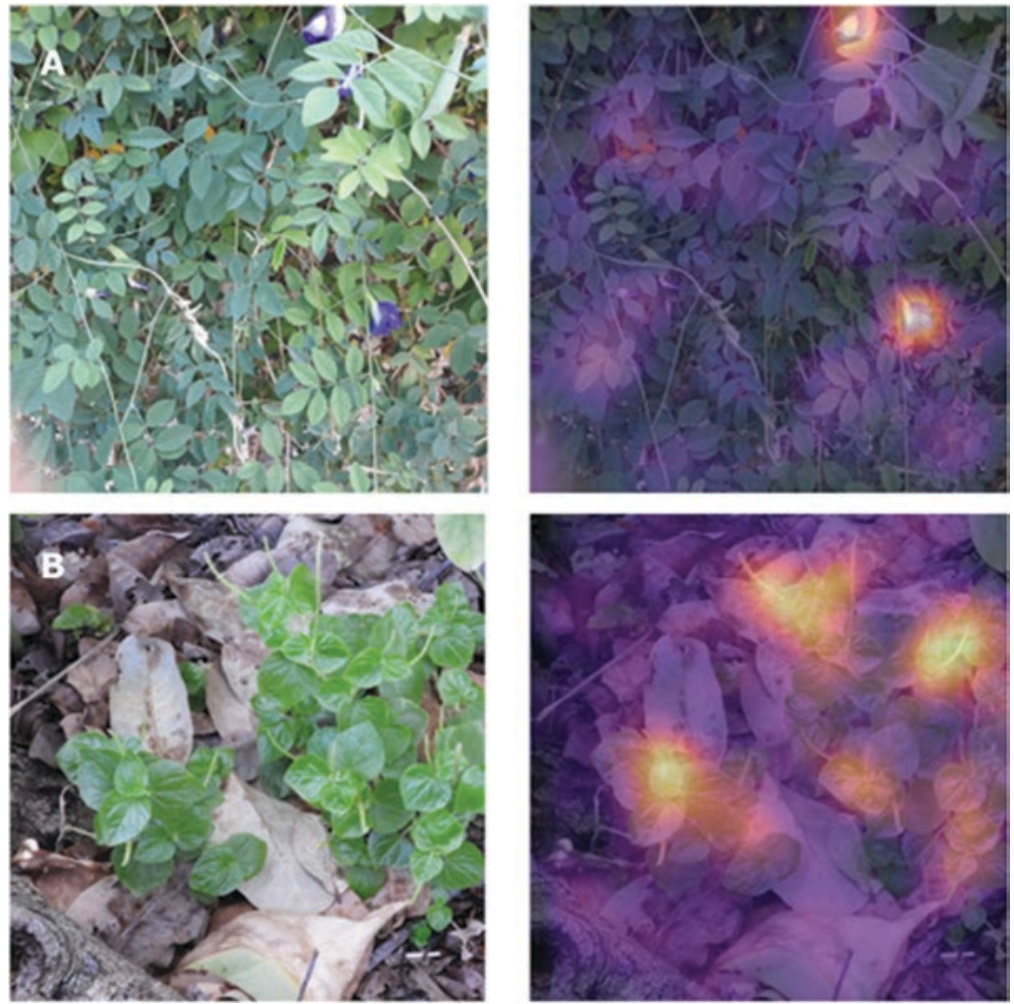

Fig. 1 Mapping the regions of the image used by AI to identify plants. (a) Grad-CAM visualization for $C$. ternatea, highlighting its leaves and blue flowers. (b) Grad-CAM visualization for $P$. pellucida, highlighting its leaves and inflorescences

pose a challenge for the deployment phase, especially for the user interface, which needs to account for user out-of-context submissions. As an example, in one case, a child took a selfie and submitted it for analysis. A plant label was assigned to her photo.

During our beta test, we implemented three measures to mitigate such problems. First, we informed users regarding how the model is trained to identify only listed species. Second, a threshold level before showing results for final use was selected, such that the user interface refrains from showing any results if the maximum probability for a given class is below the threshold. Finally, we provided differing interpretations for each probability interval, which was easily achieved with colorcoded results. In this case, we decided to hide results with a $p<=0.6$, display progress bars in red $(0.6>p>0.7)$, yellow $(0.7>p>0.85)$, and green $(p>=0.85)$, and always provide a warning concerning the intrinsic uncertainty of the model. This caution is especially important since we are working with food plants, and we need to avoid any risk of undesirable consumption. 
Any final implementation must also possess other security checks, like collecting GPS metadata from the photo itself, to ensure it comes from a plant inside the garden. Alternatively, if a WiFi connection were available in the garden, the service could be rendered inaccessible to those outside of the local network. Such security measures may reduce misuse and guide users to understand the tool's limitations better.

\section{Educational Implications of NEIDE and Other Innovative Methods}

All considered, educators seeking to foster species literacy in their own projects will value tools like ours since they may stimulate spontaneous and autonomous learning concerning plants. If applied in proper pedagogical proposals, people of different age groups can benefit from projects using apps like NEIDE, whether individually or collectively.

Community and school gardens are environments that create unique opportunities to increase environmental awareness and biocultural diversity (Vandebroek et al. 2020). For this reason, they are also strategic spaces for developing and using plant identifiers with pedagogical purposes. We highly recommend that educators use tools as trained for in controlled spaces, where they can count on a well-known plant inventory. A plant list can increase the educators' ability to prepare and invest their students (and other users) with species literacy. Tech is a tool to facilitate the learning process. The educator's role remains irreplaceable: to foster debates, to provide context, and to enhance user's and students' capacity toward thinking in broader terms, particularly about the presence or absence of UFP in local markets.

During the web-based app activities, the user can collaborate to improve the model even as the tool allows active information searches. If the tool is used only locally, data generated concerning improvement of the model may also foster both discussions and the students' potential to instruct the model. Students can also be stimulated to take notes and/or print-screens of the processing results, or of other observations made in the field to debate in class. Details in pictures, for example, can serve as kick-starters for discussing various science education topics, from botany to tech.

In Brazil, biodiversity is one of the themes included in the "National Common Curricular Base" (Marconces 2018). One of the main challenges for implementing technological innovations in addressing the theme is the scarcity of physical resources and qualified personnel in schools. According to data from PISA, the "Program for International Student Assessment," Brazilian schools average 22.1 students per computer. The country is second only to Turkey and Tunisia, respectively, with 44.9 and 53.1, and is well behind the average of the countries in the "Organization for Economic Cooperation and Development" (OECD 2015), which is 4.7. The same report has demonstrated that one in four Brazilian teachers 
reports needing professional training in information technology to improve their teaching skills. Finally, data from the 2018 "Brazilian School Census" reveal that only $44 \%$ of schools possess a science laboratory (Instituto Nacional de Estudos e Pesquisas Educacionais Anísio Teixeira 2019), an essential space for experimentation, hypothesis testing, and consolidation of ideas (Krasilchik 2008; Alexander and Mar 2017). Our proposal, which uses mobile devices and community gardens, may thus be adequate for the country's scenario. The problem regarding teachers' low capacity to deal with information technology can be addressed through multiprofessional initiatives, involving support of extension projects from the university.

\section{Final Considerations}

In this chapter, we argued that using technology and innovative methods may provide a better approach to biodiversity education. We also revealed a practical how-to example of developing a web-based app with AI to identify UFP, which may be useful to guide those supporting biodiversity projects in education. We have also demonstrated that there is no need for large datasets when training deep CNNs. This is due to the ease with which one can apply completely unrelated classification tasks through transfer learning.

The use of NEIDE, or another similar tool, may open opportunities to build knowledge, not just in biodiversity but also in AI. We believe that even data collection (the most involved arduous step) can become part of the educational activities, where participants engage with the environment to better understand how computers themselves learn. Educating people to comprehend the basics in AI will also increase the likelihood of a more diversified societal debate - including diverse gender, social class, and ethnicity. As in biology, diversity in AI will be critical to building a more comprehensive portrait of our plants (including the neglected ones), animals, landscapes, ethnicities, and cultural diversity.

Acknowledgments We dedicate this chapter to our beloved friend Ivanilda Feitosa who suddenly left us. We feel thankful for all friendship and knowledge shared.

\section{References}

Aldhebiani AY (2018) Species concept and speciation. Saudi J Biol Sci 25:437-440. https://doi. org/10.1016/j.sjbs.2017.04.013

Alexander Y, Mar O (2017) Enseñanza y Aprendizaje de las Ciencias the teaching of biodiversity: trends and challenges in pedagogical experiences. Revista Góndola 12:173-185. https://doi. org/10.14483/23464712.11599

Balmford A (2002) Why conservationists should heed Pokemon. Science 295:22367. https://doi. org/10.1126/science.295.5564.2367b 
Bebbington A (2005) The ability of A-level students to name plants. J Biol Educ 39:63-67. https:// doi.org/10.1080/00219266.2005.9655963

Bodhwani V, Acharjya DP, Bodhwani U (2019) Deep residual networks for plant identification. Proc Comput Sci 152:186-194. https://doi.org/10.1016/j.procs.2019.05.042

Celis-Diez JL, Muñoz CE, Abades S et al (2017) Biocultural homogenization in urban settings: public knowledge of birds in city parks of Santiago, Chile. Sustainability (Switzerland) 9:485490. https://doi.org/10.3390/su9040485

Cunha NR, Lima JE, Gomes MF, Braga MJ (2008) A intensidade da exploração agropecuária como indicador da degradação ambiental na região dos cerrados, Brasil. Rev Econ Sociol Rural 46:291-323. https://doi.org/10.1590/S0103-20032008000200002

da Fonseca LR, Ramos P (2019) Ensino de botânica na licenciatura em Ciências Biológicas em uma universidade pública do Rio de Janeiro: contribuições dos professores do ensino superior. Ensaio Pesquisa em Educação em Ciências (Belo Horizonte) 20:1-23. https://doi. org/10.1590/1983-211720182001026

da Silva CM (2018) Between fenix and ceres: the great acceleration and the agricultural frontier in the brazilian cerrado. Varia Historia 34:409-444. https://doi.org/10.1590/0104-87752018 000200006

de Fonseca MJ (2007) A biodiversidade e o desenvolvimento sustentável nas escolas do ensino médio de Belém (PA), Brasil. Educacao e Pesquisa 33:63-79. https://doi.org/10.1590/ s1517-97022007000100005

Deng J, Dong W, Socher R et al (2009) ImageNet: a large-scale hierarchical image database. In: 2009 IEEE conference on computer vision and pattern recognition. IEEE, pp 248-255

Engstrom L, Tran B, Tsipras D et al (2019) Exploring the landscape of spatial robustness. In: proceedings of the 36th international conference on Machine Learning, pp 1802-1811

European Commission (2013) Attitudes towards biodiversity. Flash Eurobarometer 379:1-145

Feitosa IS, Sobral A, Monteiro JM et al (2017) Impact of collection on bark regeneration from Stryphnodendron rotundifolium Mart in northeastern Brazil. Environ Monit Assess 189:1-11. https://doi.org/10.1007/s10661-017-5908-4

Feldman J (2001) Artificial intelligence in cognitive science. In: International Encyclopedia of the Social \& Behavioral Sciences. Elsevier, Oxford pp 792-796

Gatti FN (2019) Educação básica e inteligência artificial: perspectivas, contribuições e desafios. Dissertation, Pontifícia Universidade Católica

He K, Zhang X, Ren S, Sun J (2016) Deep residual learning for image recognition. In: 2016 IEEE conference on computer vision and pattern recognition (CVPR). IEEE, pp 770-778

Hemingway C, Adams C, Stuhlsatz M (2015) Digital collaborative learning: identifying what students value. F1000 Res 74:1-13

Hooykaas MJD, Schilthuizen M, Aten C et al (2019) Identification skills in biodiversity professionals and laypeople: a gap in species literacy. Biol Conserv 238:1-10. https://doi.org/10.1016/j. biocon.2019.108202

Howard J, Gugger S (2020) Fastai-a layered API for deep learning. Information 11:1-27

Instituto Nacional de Estudos e Pesquisas Educacionais Anísio Teixeira (2019) Noventa e cinco por cento das escolas de ensino médio têm acesso à internet, mas apenas $44 \%$ têm laboratório de ciências. In: INEP. http://portal.inep.gov.br/artigo/-/asset_publisher/B4AQV9zFY7Bv/ content/dados-do-censo-escolar-noventa-e-cinco-por-cento-das-escolas-de-ensino-mediotem-acesso-a-internet-mas-apenas-44-tem-laboratorio-de-ciencias/21206\%0D. Accessed 28 Jan 2020

Intergovernmental Science-Policy Platform on Biodiversity and Ecosystem Services (2019) The global assessment report on biodiversity and ecosystem services - summary for policy makers. IPBES, pp 1-56

Jiménez A, Monroe MC, Zamora N, Benayas J (2017) Trends in environmental education for biodiversity conservation in Costa Rica. Environ Dev Sustain 19:221-238. https://doi.org/10.1007/ s10668-015-9734-y 
Kelling S et al (2013) eBird: a human/computer learning network to improve biodiversity conservation and research. AI Magazine, Spring 10-21

Krasilchik M (2008) Prática de Ensino de Biologia. 6th edn. Edusp, São Paulo

Kwok R (2019) AI empowers conservation biology. Nature 567:133-134. https://doi.org/10.1038/ d41586-019-00746-1

Lima ILP, Scariot A, de Medeiros MB, Sevilha AC (2012) Diversidade e uso de plantas do cerrado em comunidade de geraizeiros no norte do estado de Minas Gerais, Brasil. Acta Botanica Brasilica 26:675-684. https://doi.org/10.1590/S0102-33062012000300017

Luckin R, Holmes W, Griffiths M, Forcier L (2016) Intelligence unleashed: an argument for AI in education. Pearson, London

March KA (2012) Backyard botany: using GPS technology in the science classroom. Am Biol Teach 74:172-177

Marconces M (2018) As Ciências da Natureza nas $1^{\text {a }}$ e $2^{\text {a }}$ versões da Base Nacional Comum Curricular. Estudos Avançados 32:269-284. https://doi.org/10.1590/ s0103-40142018.3294.0018

Mehdipour Ghazi M, Yanikoglu B, Aptoula E (2017) Plant identification using deep neural networks via optimization of transfer learning parameters. Neurocomputing 235:228-235. https:// doi.org/10.1016/j.neucom.2017.01.018

Navarro-Perez M, Tidball KG (2011) Challenges of biodiversity education: a review of education strategies for biodiversity education. Int Electr J Enviro Educ 2:13-30. https://doi. org/10.18497/iejee-green.65475

Neves A, Bündchen M, Lisboa CP (2019) Cegueira botânica: é possível superá-la a partir da Educação? Ciência \& Educação (Bauru) 25:745-762. https://doi.org/10.1590/1516-73132019 0030009

Novacek MJ (2008) Engaging the public in biodiversity issues. In: Proceedings of the National Academy of Sciences of the United States of America, pp 11571-11578

Nunes AT, Nascimento VT, Feitosa IS et al (2012) Caatinga plants with nutritional potential: a review from the work "contribution to the study of the Flora from Pernambuco, Brazil" (1954) by Dárdano de Andrade Lima. Ethnobiol Conserv 5:1-18. https://doi.org/10.15451/ ec2012-8-1.5-1-18

OECD (2015) Students, computers and learning: making the connection. PISA, OECD, Paris

Papert S (1985) LOGO: Computadores e educação. Editora Brasiliense, São Paulo

Pfeiffer VDI, Gemballa S, Jarodzka H et al (2009) Situated learning in the mobile age: mobile devices on a field trip to the sea. Alt-J 17:187-199. https://doi.org/10.1080/0968776090324 7666

Randler C (2008) Teaching species identification - a prerequisite for learning biodiversity and understanding ecology. Eurasia J Math Sci Technol Educ 4:223-231. https://doi.org/10.12973/ ejmste/75344

Rogers Y, Price S, Fitzpatrick G et al (2004) Ambient wood: designing new forms of digital augmentation for learning outdoors. Proceedings of the 2004 Conference on Interaction Design and Children: Building a Community, IDC 2004 3-10. https://doi.org/10.1145/1017833. 1017834

Rozzi R (2013) Biocultural ethics: from biocultural homogenization toward biocultural conservation. In: Linking ecology and ethics for a changing world: values, philosophy, and action. Springer, Dordrecht, Netherlands, pp 9-32

Ruiz Vicente F, Zapatera A, Montes N, Rosillo N (2020) Steam robotic puzzles to teach in primary school: a sustainable city project case. In: Merdan M, Lepuschitz W, Koppensteiner G, Balogh R, Obdržálek D (eds) Advances in intelligent systems and computing. Springer, New York, pp 65-76

Salatino A, Buckeridge M (2016) Mas de que te serve saber botânica? Estudos Avancados 30:177_ 196. https://doi.org/10.1590/S0103-40142016.30870011 
Selvaraju RR, Cogswell M, Das A et al (2020) Grad-CAM: visual explanations from deep networks via gradient-based localization. Int J Comput Vis 128:336-359. https://doi.org/10.1007/ s11263-019-01228-7

Shaha M, Pawar M (2018) Transfer learning for image classification. In: 2018 second international conference on electronics, communication and aerospace technology (ICECA). IEEE, pp 656-660

Silva JR (2013) Concepções dos professores de botânica sobre ensino e formação de professores. Thesis, Universidade de São Paulo

Simonyan K, Zisserman A (2015) Very deep convolutional networks for large-scale image recognition. In: Published as a conference paper at ICLR 2015, pp 1-14

Skinner BF (1972) Tecnologia do ensino. Ed. da Universidade de São Paulo, São Paulo

Smith LN, Topin N (2017) Super-convergence: very fast training of neural networks using large learning rates. In: Pham $\mathrm{T}$ (ed) Proceedings of Artificial Intelligence and Machine Learning for Multi-Domain Operations Applications, Spie Defense, Baltimore. https://doi. org/10.1117/12.2520589

Snyder LJU, Cathey SE, Quesenberry K et al (2012) Evaluation of CROPVIEW as a crop science teaching resource for post-secondary educators. NACTA J 56:64-69

Soga M, Gaston KJ (2016) Extinction of experience: the loss of human-nature interactions. Front Ecol Environ 14:94-101

Souza B, Artigas R, Lima E (2015) Caatinga and desertification. 131-150. https://doi.org/10.4215/ RM2015.1401

Sun Y, Liu Y, Wang G, Zhang H (2017) Deep learning for plant identification in natural environment. Comput Intell Neurosci 2017:1-7. https://doi.org/10.1155/2017/7361042

Sung YT, Chang KE, Liu TC (2016) The effects of integrating mobile devices with teaching and learning on students' learning performance: a meta-analysis and research synthesis. Comput Educ 94:252-275. https://doi.org/10.1016/j.compedu.2015.11.008

Thanh T, Nguyen N, Le VT et al (2016) Flower species identification using deep convolutional neural networks. In: Regional Conference on Computer and Information Engineering

United Nations Environment Programme (2019) Gaming for the planet: how green tech can help us care. In: UN. https://www.unenvironment.org/news-and-stories/story/gaming-planet-howgreen-tech-can-help-us-care. Accessed 27 Jan 2020

Vandebroek I, Pieroni A, Stepp JR et al (2020) Reshaping the future of ethnobiology research after the COVID-19 pandemic. Nat Plants 6:723-730. https://doi.org/10.1038/s41477-020-0691-6

Wilson EO (1984) Biophilia. Harvard University Press, Cambridge, MA

Wilson EO (2003) The encyclopedia of life. Trends Ecol Evol 18:77-80. https://doi.org/10.1016/ S0169-5347(02)00040-X

Yli-Panula E, Jeronen E, Lemmetty P, Pauna A (2018) Teaching methods in biology promoting biodiversity education. Sustainability (Switzerland) 10:1-18. https://doi.org/10.3390/su10103812

Zamora N, Calvo A (2012) Cyberhives: virtual communities of learning on biodiversity Ar. Biol Int 50:5 